\title{
Factors Influencing Quality of Life among Rural Populace in Nigeria
}

\author{
Oyeleke Ajiboye Isaac, Pius Tangwe Tanga \\ University of Fort Hare, South Africa \\ oyelekeajiboye@yahoo.com, tanga8_2000@yahoo.co.uk
}

\begin{abstract}
The study investigates factors influencing quality of life (QoL) among rural people in Nigeria. Two hundred and Twenty one (221) consenting adults within the rural area were sampled. Multi stage sampling technique was used to select respondents. Results revealed that respondents with low level of life stressor significantly reported higher score on quality of life than those with high level of life stressors. More also, there was no gender difference in the level of quality of life among the rural people. Age, gender, marital status, number of wives, number of children, and experience in rural area, occupation and educational attainment predicted quality of life. It was concluded that rural life stressor and demographic characteristics are significantly related to rural dwellers quality of life.
\end{abstract}

Keywords: Rural behaviors, stress, demographic characteristics and quality of life

\section{Introduction}

Quality of life for the rural populace is multifaceted and involves an aggregate interaction of factors such as level of income, living standard, quality of habitation and access to infrastructure facilities (Zaid \& Popoola, 2010). Central to the quality of life among rural dwellers is the occupation and environment induced stressors; factors that lower the wellbeing of this populace. Quality of life is defined as the quality of the social indices qualifying a society. Among the arrays defining the rural society is the feeling of psychological and physical wellbeing among its populace (Zaid \& Popoola, 2010). Rural Nigeria is endowed with abundant productive land, mineral resources and teeming labor force. Despite the availability of human and material resources, the rural populace is still populated with people with low quality of life. Quality life has been identified to be out of reach for the majority of rural dwellers in Nigeria due to lack of access to clean water, health care and good roads, making the rural areas less enjoyable and difficult to live in (Meludu \& Bajowa, 2008). Therefore, the rural populace is described as people with poor mental health and closely linked to occupational and environment stress factors (Meludu \& Bajowa, 2008).

Besides the lack of infrastructure and basic services identified to contribute to poor quality of life among rural communities in Nigeria, occupational induced stress remains the major factor limiting positive psychological health in these communities. Farming activities are the major important occupation of people in the rural areas in Nigeria (Mgbada, 2010; Ekong, 2010). Some combine these activities with artisan work or public services (Adepoju and Obayelu, 2013). Lack of infrastructure leaves the farmers working with crude technology and stressful processes which greatly affects their quality of life (Nzenwa, 2005). Farming stress defines facets of farm work and environmental factors inducing distress among farmers. These include farm operations such as land clearing, preparation and harvesting. Farming stresses also include anxiety about environmental uncertainties such as weather, the health of the crops, the market and policy that may present challenges to a successful farming season. Uncontrollable factors common to weather seasonality are unpredictable; and these include adverse weather conditions, disease epidemics and natural disasters (flooding and drought). Factors relating to human activities include instability of market prices and government policies.

Available literature indicates that no study has empirically ascertained the role of farming stress factors in rural Nigerian communities. Further, several works on quality of life have focused on characteristics and access to infrastructure of rural people, with no investigations on the role of the occupational stressors on quality of life of rural communities (Akinyemi, Owoaje, Popoola \& Ilesanmi, 2012). This paper sought to answer four research questions, which are:

$>$ What is the relationship between dimensions of rural farming stress, family stressors, government policy, illness, financial problems, machinery, workers, weather problems and quality of life?

$>$ Does farming stress affect the level of quality of life in rural communities?

$>$ Is gender a determinant in quality of life of rural people in Nigeria? 
What contributions do age, gender, marital status, family size, number of wives, residency experience in the rural area, and educational attainment have on quality of life

\section{Literature Review}

Studies have indicated that rural residency poses a serious challenge to mental health of the rural populace (Akinyemi et al., 2012). There are a number of factors that literature has consistently identified as making farming a distinctively stressful occupation. Causes of agricultural stress include financial problems, the political climate, workload and time pressures, diseases and acute crises, seasonality and adverse weather conditions, mechanical failures, family problems, health problems, acquisition and transfer issues, security, isolation and negative press coverage. Farming is the predominant employment in the rural areas and it has demonstrated to be very stressful (Meludu \& Obajowa, 2008). The United Nations Development Program's Human Development Report (2014) found that financial issues, work overload are the most prevalent stressors among farmers. The report also found that $80 \%$ of the farmers, both big and small, worry about their finances. Working for longer periods of times daily was found to have aggravated the physical and mental health of rural farmers (United Nations Development Program's Human Development Report, 2014). The Legatum Institute (2013), in a study, identified adverse seasonality, epidemics, falling prices, increasing prices of farm inputs, technological failures, governmental policy somersault and lack of child care facilities as major stressors influencing poor mental health among rural farmers. Har and Zia (2014) also corroborated that poor policy implementation, financial and time pressures induced acute stress among Welsh farmers.

Thorn's (2010) research with farmers using the Revised Clinical Interview Schedule established that farmers had a lower-than-average level of psychiatric problems, but higher levels of suicidal thoughts, particularly amongst rural and semi-rural households. Many of the factors causing mental and emotional stress are viewed as uncontrollable, and include weather, diseases or pests, commodity prices, input costs, equipment failure, media portrayal of the agricultural industry, government policies and lack of adequate, affordable and accessible child care. Ramesh and Madhavi (2009) demonstrate that poor working conditions and prevalent negative economic situations induce high stress among farmers. As a result, Ramesh and Madhavi (2009) conclude, a significant percentage attend health clinics due to stress-related illnesses. Fasoranti (2008) found that high work demands and expectations, coupled with low control and lack of social support can lead to a poor psycho-social work environment, with increased stress levels, ill mental health, depression, and, in the worst cases, suicide. Internationally, farmers with mental illnesses have different health service options depending on their location. Regardless of location, it is initially the responsibility of the individual farmer and farmer family to handle mental health and stress, which can be of short or long-term duration. In Nigeria, Meludu and Bajowa (2008) found the influence of farming related problems in social and psychological related stress but found differences between poultry and cassava farmers. Momodu (2002) developed a measure for farm stress. With the help of the data collected from 362 farmers using factor analysis they came up with factors like life satisfaction, emotional strain, illness frequency, personal finances and time pressures. Among these five factors, personal finances and time pressures were found to be the most significant predictors of farm stress.

Eurofound (2014) found gender differences in wellbeing in rural Australia and significant lower prevalence of mental health problems in rural areas. Women demonstrate positive well-being than their men counterpart as a result of differences in adaptation to mental health problem. Qualitative research in Australia suggests that within the rural community, mental illness is equated with severe mental illness such as psychosis, which often requires detention (Firth, 2001). Other symptoms of mental illness were more likely to be attributed to problems such as financial worries. A comparative study found that young men with mental health problems in rural Australia were less likely to seek help than their urban counterparts (Hembry, 2008). Likewise, research in rural Scotland (Scottish Executive, 2006) found that stress, anxiety and depression were less likely to be recognized as mental health problems requiring treatment.

Theoretical Orientation-Integrative quality of life theory: The Integrative quality of life theory seeks to measure the quality of life at a global level. It is a comprehensive theory or meta-theory that includes eight theories in a subjective-existential-objective spectrum. According to this theory, quality of life refers to a pleasant life lived in high quality. There are different meanings attached to quality of life by different religions 
and philosophies. These may include the notion that a good life is enhanced by having a positive attitude towards life or by knowing oneself deeply. Quality of life can be divided into three groups, each dealing with an aspect of a pleasant life. There is the subjective quality of life that has to do with life satisfaction and how happy the individual is in life. It has many aspects, which include satisfaction with life, happiness, and meaning in life. When an individual is positive in all these aspects it is believed that such a person is having good quality of life. However, a good life is far more than being satisfied, happy and having meaning for life. The existential quality of life indicates how pleasant an individual feels deep down or how harmonious one's life is. In actual sense it simply means that quality of life is the agreement between a life lived and a sense of deep inner feeling of self-actualization. Two aspects constituting the biological view of quality of life are realizing life's potential and fulfillment of needs.

The objective quality of life on the other hand refers to how others view one's life, which is influenced by culture. It refers to how a person is able to conform to the values of his/her culture, which can be seen in such a person's life. Some of the aspects of objective quality of life include income, marital status, state of health and the amount of relationships with others. In essence, objective quality of life emphasizes the conformity to societal norms and values as a sign of quality of life. This theory provides an elaborate way of measuring quality of life that includes concepts that are expressible and measurable and those that are inexpressible and immeasurable. However, the existential level, which is deep down in a human, is the center that produces the meaning to life and the center of human being. It is the reflector of quality of life and where in-depth knowledge of a human being could be attained. However, this experience at this level cannot be expressed because it is not rational and it is from this deepest pool that humans consider essence of life to emanate. Rural dwellers are subjected to denial of many amenities of life as a result of deliberate neglect by government. Such infrastructure as tarred roads, electricity, pipe borne water and good health care facilities are mostly not available in many rural areas and these have a toll on the quality of life (Development Support Monitor, 2012). Their life experiences, both subjective and objective, in most cases are negative and this may denote their quality of life. However, considering the integrative quality of life theory, both subjective and objective experiences may not be enough to measure their quality of life as it is possible for them to have the real meaning of life deep down within them despite their subjective and objective life experience. They may be satisfied with life despite what life has to offer them.

\section{Methodology}

This study adopted a cross-sectional design. The population of this paper was made up of people living within Otu town, the headquarters of Iwajowa LGA of Oyo state, Nigeria. Two hundred and twenty one (221) consenting male and female adults aged 18 years and above were sampled as respondents using the multi stage sampling technique. The town was divided into 10 enumeration areas using the cluster sampling method. A total of four (4) enumeration areas were randomly selected from the 10 clusters. Each enumeration area had 15-30 households and about 350-450 people. The purposive sampling technique was used to select participants at their various households. The research instrument used in the study was a standardized self-report questionnaire divided into four sections. The questionnaire elicited biographical information, which included years of experience and occupations of respondents. The WHO quality of life (WHOQOL-BREF) questionnaire was used to measure physical health, psychological (mental) health and social relationships of respondents. The WHOQOL-BREF has a meritorious reliability $(\alpha=0.86)$ (Gureje, Kola, Afolabi \& Olley, 2012). High scores on the WHOQOL-BREF indicate better quality of life. Rural people life stressors were measured using items adapted from the Farm Stress Scale developed by Araquistain (1992). The 13-item scale measures stressors experienced by the rural populace in farming activities, with a good psychometric property $(\alpha=.85)$. The research instrument was translated to Yoruba, the predominant local language and the data back-translated to English to ensure the original meaning was retained. A pilot study was conducted in a town not included in the study. Twenty questionnaires were pretested and appropriate amendments were made after the Pilot study. For this paper, the scale recorded a reliability index of 0.87 cronbach alpha. Informed consent was obtained from participants before the administration of questionnaires. Useable questionnaires were analyzed using descriptive statistics, the Pearson Product Moment Correlation analysis, t-test and multiple regression analysis at 0.05 level of significance to test inferred relationship and differences among the variables. 


\section{Results}

The relationship between farming stressors and quality of life was tested using the Pearson Product Moment Correlation. This is illustrated in table 1 below.

Table 1: Pearson Product Moment Correlation of farming stressors and quality of life

\begin{tabular}{llllllllll}
\hline Variables & Mean & SD & 1 & 2 & 3 & 4 & 5 & 6 & 7 \\
\hline 1.Quality of life & 42.46 & 4.36 & - & & & & & & \\
2.Family Stressor & 13.51 & 1.88 & $-.69^{* *}$ & - & & & & & \\
3.Government policy & 3.59 & .93 & $-.63^{* *}$ & $.58^{* *}$ & - & & & & \\
4.Illness & 7.47 & 3.75 & $-.69^{* *}$ & $.61^{* *}$ & $.51^{* *}$ & - & & & \\
5.Financial problem & 14.44 & 2.32 & $-.63^{* *}$ & $.59^{* *}$ & $.50^{* *}$ & $.54^{* *}$ & - & & \\
6.Machinery/workers & 9.86 & 2.13 & $-.79^{* *}$ & $.67^{* *}$ & $.65^{* *}$ & $.68^{* *}$ & $.73^{* *}$ & - & \\
Problems & 7.52 & 1.21 & $-.52^{* *}$ & $-.32^{* *}$ & $-.22^{* *}$ & $-.31^{* *}$ & $.22^{* *}$ & $-30^{* *}$ & - \\
7.Weather problem & 7.
\end{tabular}

**Correlation is significant at the 0.01 level (2-tailed). *Correlation is significant at the 0.05 level (2-tailed).

Table 1 above reveals that there was a significant inverse relationship between family stressors and quality of life $(r=-.69, p<.01)$, indicating that increasing family stressors significantly relate to a decrease in quality of life. There was significant inverse relationship between government policy and quality of life $(r=-.63, p<.01)$. This implies that an increase in implementation of government policies was significantly associated with poor quality of life within rural communities. Further, significant inverse relationship was observed between frequent experience of illness and quality of life $(r=-.69, p<.01)$. The rural people were experiencing frequent bouts of illness and this denoted poor quality of life. Negative inverse relationship was also observed between financial problems $(\mathrm{r}=-.63, \mathrm{p}<.01)$, machineries and workers stressors $(\mathrm{r}=-.79, \mathrm{p}<.01)$ on one hand and quality of life on the other. This demonstrates that an increase in financial problems significantly relates to a decrease in the quality of life. Analysis also revealed that there was a significant relationship between machineries and workers on one hand and quality of life on the other. This implies that an increase in problems of machineries and workers significantly relates to a decrease in the quality of life. There was a significant inverse relationship between weather unpredictability and quality of life $(\mathrm{r}=-.52, \mathrm{p}<.01)$. This indicates that unfavorable weather conditions significantly induced poor quality of life. Differences in the respondents' quality of life, based on the level of farm stress, were tested using the t-test for independence and the results are presented in Table 2 below.

Table 2: Here t-test summary table showing difference in the level quality of life based on level of exposure to Farming Stressors

\begin{tabular}{llllllll}
\hline & Farm Stress & N & Mean & S.D & df & T & P \\
\hline \multirow{2}{*}{ Quality of life } & Low & 121 & 42.52 & 4.29 & \multirow{2}{*}{221} & 2.29 & $<0.05$ \\
& High & 100 & 35.50 & 9.19 & & & \\
\hline
\end{tabular}

The data presented in Table 2 above show that farmers who experienced low farm stress ( $\bar{x}=42.52, \mathrm{~S} . \mathrm{D}=4.29)$ significantly reported better quality of life than those high on farm work stressors $(\bar{x}=35.50$, S.D $=9.19), \mathrm{t}$ $(150)=2.29, \mathrm{p}<.05$. This implies that life stressors significantly influence quality of life. Differences in the quality of life between male and female farmers were analyzed using the t-test for independence and the results are presented in Table 3 below. 
Table 3: t-test summary table showing the influence of gender on quality of life

\begin{tabular}{llllllll}
\hline & Gender & N & Mean & S.D & df & T & P \\
\cline { 2 - 8 } Quality of life & Male & 115 & 42.28 & 4.28 & 220 & -.79 & $>0.05$ \\
& Female & 107 & 42.74 & 4.38 & & & \\
\hline
\end{tabular}

Analysis of data in table 3 shows that male respondents ( $\bar{x}=42.28$, S.D $=4.28)$ were not significantly different in the level of quality of life when compared to female respondents $(\bar{x}=42.74, \mathrm{~S} . \mathrm{D}=4.38) \mathrm{t}(220)=-.79, p>.05$. Gender did not influence the quality of life among the respondents sampled. The joint contributory influence of age, gender, marital status, number of wives, number of children, and experience in rural area, occupation and educational attainment was investigated using Multiple Regression Analysis (MRA). The results are presented in Table 4 below.

Table 4: Summary of Multiple Regression Analysis showing the contributions of socio-demographic variables to quality of life

\begin{tabular}{|c|c|c|c|c|c|c|c|}
\hline Predictors & $\beta$ & $\mathbf{t}$ & $\mathbf{P}$ & $\mathbf{R}$ & $\mathbf{R}^{2}$ & $\mathbf{F}$ & $\mathbf{P}$ \\
\hline Age & -.12 & -1.21 & $>.05$ & & & & \\
\hline Gender & .08 & 1.14 & $>.05$ & & & & \\
\hline Marital status & .02 & .31 & $>.05$ & & & & \\
\hline Number of wives & .15 & 1.91 & $>.05$ & 0.50 & 0.25 & 8.58 & $<.01$ \\
\hline Number of children & .27 & 2.95 & $<.01$ & & & & \\
\hline Years of residency in rural area & -.42 & -5.42 & $<.01$ & & & & \\
\hline Occupation & -.10 & -1.60 & $>.05$ & & & & \\
\hline Educational attainment & -.26 & -3.52 & $<.01$ & & & & \\
\hline
\end{tabular}

Results revealed that age, gender, marital status, number of wives, number of children, experience in rural areas, occupation and educational attainment jointly predicted and accounted for $25 \%$ of the change observed in the quality of life $\left(\mathrm{R}^{2}=0.25, \mathrm{~F}(8,212)=8.58, \mathrm{p}<.01\right)$. The results also revealed that the number of children $(\beta=.27, \mathrm{p}<.01)$, experiences in rural area $(\beta=-.42, \mathrm{p}<.01)$ and educational qualification $(\beta=-.26$, $p<.01)$ were significant independent predictors of quality of life. Age $(\beta=-.12, p>.05)$, gender $(\beta=-.08, p>.05)$, marital status $(\beta=.02, p>.05)$, number of wives $(\beta=.15, p>.05)$ and occupation $(\beta=-.10, p>.05)$ had negligible influence on quality of life. Increasing number of children, negative experiences and educational qualifications significantly influenced quality of life.

Discussion: The relationship between family stressors, government policy, illness, financial problems, machineries and workers and weather problems on one hand and quality of life on the other was confirmed. There was significant inverse relationship between quality of life and such factors as family, government policy, illness and financial problem, faulty machineries, problems with workers and weather problems. This was expected as rural areas in Nigeria were largely underdeveloped, with poor health care and finance facilities. The various agriculture policies have since been hijacked by politicians. Distribution of fertilizers and farm inputs is largely politicized and beneficiaries are short-changed. The findings above support the findings from Ward and Tanner (2010) who found that farm stressors were associated with poorer HRQOL in farm workers. In the same vein, Morais, Miguéis and Camanho (2013) demonstrated that policy implementation, financial issues and work overload were stress inducing factors affecting QOL. Najafpour, Bigdeli Rad, Lamit and Fitry (2014) also demonstrated that incidence of illnesses affected quality of life. In consonance, Norouzian-Maleki, Bell, Hosseini and Faizi (2015) also associated levels of psychiatric problems with farm stressors. Findings of the current study are similar to Stimson and Marans (2011) who indicated that financial pressures and longer work durations reduced quality of life among rural farmers.

The results of the current study also demonstrate that significant differences did not exist in the level of quality of life between male and female rural inhabitants. This is rather unusual as females tend to bear the greater part of family burden and problems with farm workers compared to their male counterparts. These findings, however, are similar to those of Meludu and Obajowa (2008) as they also found no gender 
differences in stress levels and wellbeing among farmers. This, though, is in contrast with Ramli, Yassin, Idris, Hamzah, and Abu Samah, (2013) who found gender differences in rural Australia. Larger numbers of children, years spent living in the rural area and educational qualifications were significant predictors of quality of life while the influence of age, gender marital status, number of wives and occupation were not significant. Increasingly, family size is no longer advantageous to poor rural farmers as the cost of child rearing is getting higher. For example, with the collapse of social facilities such as education and health care services in rural areas, farmers spend greater part of their income securing better education and health care for their children in the urban centres. These findings are similar to findings by Flor, Campos and Laguardia (2013) who established that good quality of life was explained by sex, age, education, number of aggravations and smoking. Young, well-educated and healthy younger individuals had better quality of life than older people. Rural dwellers in Nigeria cannot score high on the global measurement of quality of life because, subjectively and objectively, they are very low according to integrative quality theory. These rural dwellers are subjected to stress as a result of farming activities and are often victim to ill health, which reduces quality of life. Non availability of amenities and infrastructure are factors that increase stress, which in turn affects the health of the rural people. Quality of life is all about health and illness. Better quality of life for the rural populace in Nigeria would, therefore, be a situation whereby stressors are removed through provision of infrastructure and amenities through which there can be balance of the subjective-existential-objective spectrum.

\section{Conclusion}

Problems with workers, machinery, physical health and family size are the most stressful variables associated with poor quality of life in rural communities in Nigeria. Gender differences were not observed in quality of life. Increasing family size and longer stay at a rural area were associated with poor quality of life. This is an indication that the various interventions and developmental approaches to solving rural problems have largely not had the desired impact. For mental health practitioners there is need for advocating for the inculcation of free mental health counseling services for rural dwellers as they are less likely to seek help and have lesser resources to take up counseling services in the urban centres. There is need for urgent intervention in the rural areas of Nigeria in the area of provision of health and economic infrastructures to help farmers cope with stress associated with farming. Government should provide financial assistance to farmers in order to improve their quality of life. Further studies should endeavor to investigate the coping resources available to rural dwellers to provide further insight to the level of quality of life among the rural populace.

Implication of study for social work practice: This study has implications for rural social work practice. Rural social work is about ensuring the well-being of rural dwellers, with the aim of meeting their needs at individual and community levels through intervention programs. The study provides information for the rural social worker on the challenges of rural dwellers in Nigeria and how these people can be supported with informed policy to address their problems. Advocacy is highly needed to articulate and present the needs of rural dwellers to those who can effectively address these problems. To ensure the well-being of rural people through a quality life, rural social workers need to engage them in ways that inform on how to reduce their stress levels induced by farming activities and other stressors that are peculiar to the rural environment through periodic enlightenment programs and other means such as mental health counseling, which can ensure good quality of life. The need for enlightenment programs cannot be overemphasized.

Recommendations: In light of the findings of the study discussed and the conclusions arrived at, this study recommends the following:

- There is need for urgent intervention in the rural areas of Nigeria to provide infrastructural facilities to help farmers cope with the stress associated with farming.

- Government, at all levels, must show genuine interest in agriculture by providing financial assistance to farmers in order to improve their quality of life.

- Further study should endeavor to include physical health and environmental stressors to provide further insight the quality of life among the rural populace. 


\section{References}

Adepoju, A. O. \& Obayelu, O. A. (2013). Livelihood diversification and welfare of rural households in Ondo State, Nigeria. Journal of Development and Agricultural economics, 5(12), 482-489

Akinyemi, O. O., Owoaje, E. T., Popoola, O. A. \& Ilesanmi, O. S. (2012). Quality of life and associated factors among adults in a community in South West Nigeria. Annals of Ibadan Postgraduate Medicine (In press).

Araquistain, M. (1992). Stress, family hardiness, and perceived illness occurrence in farm and ranch families in Southwest Idaho. Master's Thesis, Unpublished. China: University of Wyoming.

Development Support Monitor. (2012). Rural infrastructure in Africa: Unlocking the African moment. Development Support Monitor Paper series No 1.

Ekong, E. (2010). Rural sociology. Dove Educational Publishers. Uyo, Nigeria.

Eurofound. (2014). Quality of Life in Urban and Rural Europe. Luxembourg: Publications Office of the European Union.

Fasoranti, M. M. (2008). Economic implication of poverty alleviation programs on rural women in Ondo-State: Case Study of Country Women Association of Nigeria. Journal of Social Science, 4(4), 352 - 357.

Firth, H. M. (2001). Health of farmers in Southland: An overview. New Zealand Medical Journal, 114 (9): 426428.

Flor, L. S., Campos, M. R. \& Laguardia, J. (2013). Quality of life, social position and occupational groups in Brazil: evidence from a population based survey. Revista Brasileira de Epidemiologia, 16 (3), 748-762.

Gureje, O., Kola, L., Afolabi, E., Olley, B. O. (2008). Determinants of quality of life of elderly Nigerians: results from the Ibadan study of ageing. African journal of medicine and medical sciences, 37(3), 239-249.

Har, R. \& Zia, U. (2013). Multidimensional well-being: an index of quality of life in a Developing economy. Social Indicator Research, 10(3), 997-1012.

Hembry, $0 . \quad$ (2009). Farmers on long road to recovery. Fromhttp://www.nzherald.co.nz/nz/news/article.cfmcid=1\&objectid=10560019 (Retrieved $5^{\text {th }}$ March, 2015).

Legatum Institute. Legatum propriety index. (2013). From: http://www.prosperity.com/\# !/.17 (Retrieved 10 March, 2015).

Meludu, N. T. \& Bajowa, O. M. (2008). Gender and Stress Coping Strategies of Poultry a Cassava Farmers in Nigeria. Journal of Human Ecology, 23(2), 159-164.

Mgbada, J. U. (2010): Agricultural Extension: The Human Development Perspective. computer Edge Publishers, Enugu.

Momodu, M. O. (2002). Information needs and information seeking behavior of rural dwellers in Nigeria: a case study of Ekpoma in Esan West Local government area of Edo State, Nigeria.

Morais, P. V., Miguéis, L. \& Camanho, S. A. (2013). Quality of Life Experienced by Human Capital: An assessment of European cities. Social Indicator Research, 110(1), 187-206.

Najafpour, H., Bigdeli, R. V., Lamit, H. \& Fitry S. M. (2014). The Systematic Review on Quality Of life in urban neighborhoods. Life Sciences Journal, 7, 355-364.

Norouzian-Maleki S., Bell, S., Hosseini S. B. \& Faizi, M. (2015). Developing and testing a Framework for the assessment of neighborhoods live ability in two contrasting Countries: Iran and Estonia. Ecological Indicators, 48, 263-271.

Nzenwa, G. (2005). Effect of Poverty on Risk Attitudes of Farmers in Benue State, Nigeria. unpublished thesis: University of Ibadan.

Ramesh, A. S. \& Madhavi, C. (2009). Occupational stress among farming people. The Journal of Agricultural Sciences, 4(3), 115-125.

Scottish Executive. (2006). Rural Scotland Key Facts 2006. Scottish Executive. From http://www.gov.scot/Publications/2006/07/31114822/3 (Accessed on 20 February, 2016).

Ramli, S. A., Yassin, S. M., Idris, K., Hamzah, A. \& Abu, S. (2013). The Quality of life of Bahau riverside community: the case of the rural community living along Muar and Serting Rivers. International Journal of Business Management, 7(2), 114-202.

Stimson, R. \& Marans, R. W. (2011). Objective Measurement of quality of life using secondary data Analysis in investigating quality of urban life: theory, method and empirical Research. Social indicators Research, 2, 43-55. 
Thorn, A. (2010). Horticulture New Zealand Homepage: Product groups. From http://www.hortnz.co.nz/Overview/Productgroups/Introduction.htm (Retrieved 3 April, 2016).

United Nations Development Program's Human Development Report. Human Development Index (2014). Available: http://hdr.undp.org/en/content/human-development-index-hdi(Retrieved 3 April, 2016).

Ward, L. S., Tanner, A. \& Officer, R. (2010). Psychological stress and health-related quality of life for Latino migrant farm workers. Southern Online Journal of Nursing, 10(1), available at: www.resourcenter.net/images/SNRS/Files/SOJNR_articles2

Zaid, Y. A. \& Popoola, S. O. (2010). Quality of life among rural Nigerian women: The role of information. From: http://digitalcommons.unl.edu/libphilprac/513/ (Retrieved 3 April, 2016). 